\title{
4 The social impact of broadband Internet in the home
}

\author{
Ben Anderson and Yoel Raban
}

\section{The broadband 'revolution'}

At the time of writing there is an almost ceaseless stream of news flashes and marketing messages trumpeting the future social and economic (not to ignore profitable) opportunities of broadband Internet access in the home. This has not gone unnoticed in policy circles since the early 1990s (Bangemann, 1994; DTI, 1994). More recently, and as a natural progression from the Bangemann report, the eEurope 2005 Action plan ${ }^{1}$ states:

broadband enabled communication, in combination with convergence, will bring social as well as economic benefits. It will contribute to einclusion, cohesion and cultural diversity. It offers the potential to improve and simplify the life of all Europeans and to change the way people interact, not just at work, but also with friends, family, community, and institutions.

(CEC, 2002: 8)

But is this happening, and what evidence do we have of the difference that broadband makes to the domestic user? This chapter uses data from the eLiving survey to assess at least some of these issues empirically.

The processes of choosing a broadband connection, the characteristics of those who do so and the possible effects this has have all been the focus of a number of academic studies, as well as many private and public market research surveys such as the Flash Eurobarometers funded by the European Commission (Gallup Europe, 2002).

Many of these studies concentrate on modelling and forecasting demand based on hypothetical price and charging schemes or potential applications and are of less interest here (see, for example, Madden and Simpson, 1997; Ida and Kuroda, 2004; Savage and Waldman, 2005).

Others have used survey data to study the characteristics of early adopters of broadband. For the USA in 2000, Kridel and colleagues (2002) found that broadband adopters tended to be younger and have higher income and education levels. For Korea, Lee et al. (2003) note that the mobilisation of 
demand through IT literacy activities particularly targeting housewives, the elderly, military personnel and farmers may have had a significant effect in driving up demand and thus uptake. They also suggest that Asian cultures, are more likely to use the Internet for inter-personal communication than non-Asian cultures and that the increased affordances for this aspect of usage may also have contributed to increased demand for broadband although, as we shall see, this may also be true of non-Asian cultures. For New Zealand, Paynter and Chung (2003) showed that early broadband adopters were more likely to be male, to be those with higher computer skills and who used the Internet more per day. Interestingly, educational status, age and income made no difference. Finally, for the UK, Robertson and colleagues (2004) found that educational attainment, disposable income and the presence of children were all indicators of Internet adoption and had a marginally stronger effect for broadband as opposed to narrowband.

A few studies have focused on patterns of usage. For example, Hoag (1998) used a single cross-sectional survey of cable modem and narrowband users in the USA to establish that there were few socio-demographic differences between the two groups (confirmed by Anderson et al. (2003), but that broadband users tended to make more use of FTP and the Web than narrowband users and also to spend more time online. She also showed that they made more use of a wider range of applications and were more satisfied with their Internet experience.

Using Pew Internet data for the USA, Horrigan and Rainie (2002) showed that broadband users spent more time online, did more things and did them more often than narrowband users. As with some of the other studies, they also suggested that home broadband users were typical early technology adopters', being disproportionately well educated, wealthy and male.

However, as we will elaborate below, such studies of difference tell us nothing at all about broadband-related changes. Indeed recent authors have noted that few academic publications focus on the impact of broadband on social and personal issues in contrast to the developmental and macro-economic issues (Firth and Mellor, 2005). Firth and Mellor note that the results of even these economic analyses tend to provide more rhetoric than empirical analysis and they call for a diverse analysis of the outcomes of broadband Internet access.

By following individuals over time, the e-Living project has produced one of the few datasets that can distinguish the effects of moving to broadband from the effects of heavy Internet users becoming broadband users. We will provide an illustrative example of this key distinction below.

Using wave one (2001) and wave two (2002) of the e-Living longitudinal household panel survey, we initially provide descriptive data on the uptake of household broadband Internet access in the six countries (UK, Italy, Germany, Norway, Bulgaria and Israel). Then, rather than repeat previous cross-sectional analyses of uptake, we use the unique longitudinal nature of the e-Living data to develop models of the 'impact' of switching to 
broadband between wave one (2001) and wave two (2002) on time spent using the Internet, social leisure, TV watching and e-commerce. We focus on these issues because they are germane to a number of academic, policy and commercial pre-occupations:

- Does broadband Internet access lead to more time being spent online? Or is it that people can do more in the same amount of time that is available to them?

- Might broadband Internet access lead to less social engagement in a dystopian future as some might suggest (Nie and Hillygus, 2002)?

- Might the usage of broadband, whether for content or for new forms of leisure, lead to a reduction in TV viewing and an attendant switch in potential advertising revenues?

- To what extent does broadband enable more (or more valuable) e-commerce transactions by households?

The chapter concludes with a summary of the results and a brief discussion of their implications.

\section{Definitions}

What do we mean by 'broadband'? According to the ITU (2003) 'Broadband is commonly used to describe recent Internet connections that are significantly faster than today's dial-up technologies, but it is not a specific speed or service.' Recommendation I.113 of the ITU Standardization Sector defines broadband as a transmission capacity that is faster than primary rate ISDN, at 1.5 or $2.0 \mathrm{Mbit} / \mathrm{s}$. Elsewhere, broadband is considered to correspond to transmission speeds equal to or greater than $256 \mathrm{kbit} / \mathrm{s}$, and some operators even label basic rate ISDN (at $144 \mathrm{kbit} / \mathrm{s}$ ) as a 'type of broadband'. In this chapter, while not defining broadband specifically, $256 \mathrm{kbit} / \mathrm{s}$ is generally taken as the minimum speed and so we use the following definitions:

- $\quad$ Analogue = narrowband Internet access (does not include ISDN).

- Broadband $=$ cable modem $/$ ADSL.

\section{Penetration of broadband Internet access in households}

To provide context to the analysis that follows, Table 4.1 compares the results of e-Living wave two with Eurobarometer (EB) 135 (2002) and ITU (2003) data to show levels of broadband Internet uptake in households in 2002. In most cases, the differences between the surveys are in the order of $+/-4$ per cent, which is to be expected. However, the e-Living results for Germany estimate fewer Internet households in general and fewer ISDN/broadband in particular than does the EB 135. Comparison with the ITU source, which also contains mostly 2002 data, suggests that whilst the 


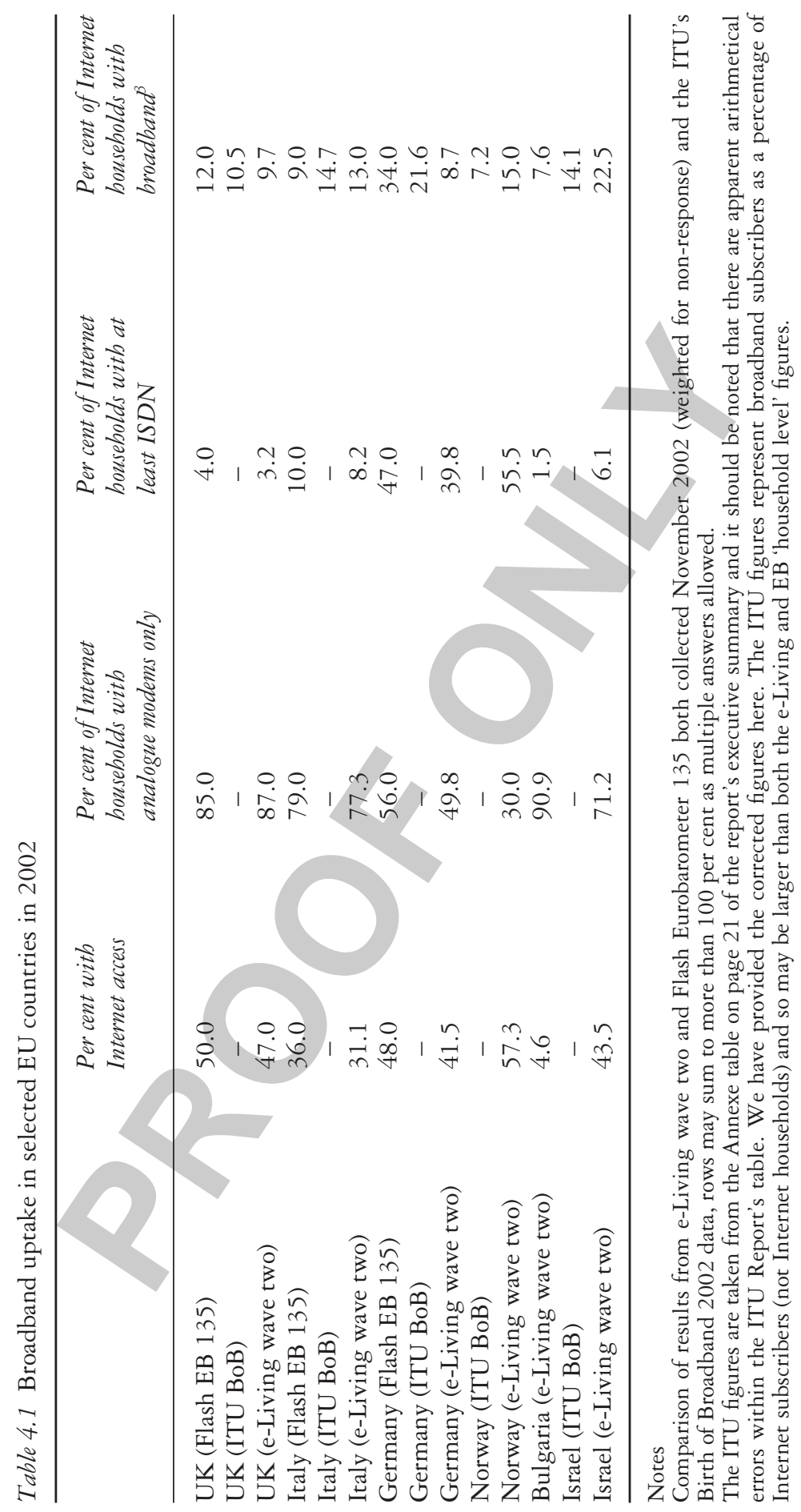


e-Living figures for Germany may have been an underestimate, the EB figures were certainly an overestimate.

However, the e-Living results suggest that, in 2002, in the e-Living countries, broadband Internet access was most prevalent in Israel and Norway, with Italy and the UK roughly equal. Bulgaria may appear to have had a broadband penetration rate within Internet households similar to that of the other countries, but this in fact represents five households! Of course this is a view of history. By 2005, these figures have changed substantially so that, for example, in the UK, more than 55 per cent of Internet households had broadband access (Dutton et al., 2005).

\section{Routes to broadband}

Even though they describe the recent past, the two waves of e-Living data provide a unique resource to analyse the routes that households are taking to broadband and, indeed, their routes out again.

Table 4.2 pools data for all six countries and suggests that about 0.7 per cent of those who had no personal computer (PC) or Internet access in 2001 had become broadband users in 2002, 3.6 per cent of those with a PC but no Internet had moved to broadband, whilst 11 per cent had a PC and narrowband Internet access before switching. On the other hand 87 per cent of those who had no PC or Internet were still in the same state and 54 per cent of those with a PC but no Internet had also not 'progressed' to Internet access of any kind. Intriguingly, some 14 per cent $(1.6+2.8+10.8)$ of those who had some form of broadband (ISDN or above) in $2001 \mathrm{had}$ reverted to narrowband, or some even to no Internet access by 2002. Clearly whilst there is adoption going on, there is also dis-adoption and considerable stasis (non-adoption).

Table 4.2 Routes to broadband (e-Living wave one and two, 2002, weighted for non-response)

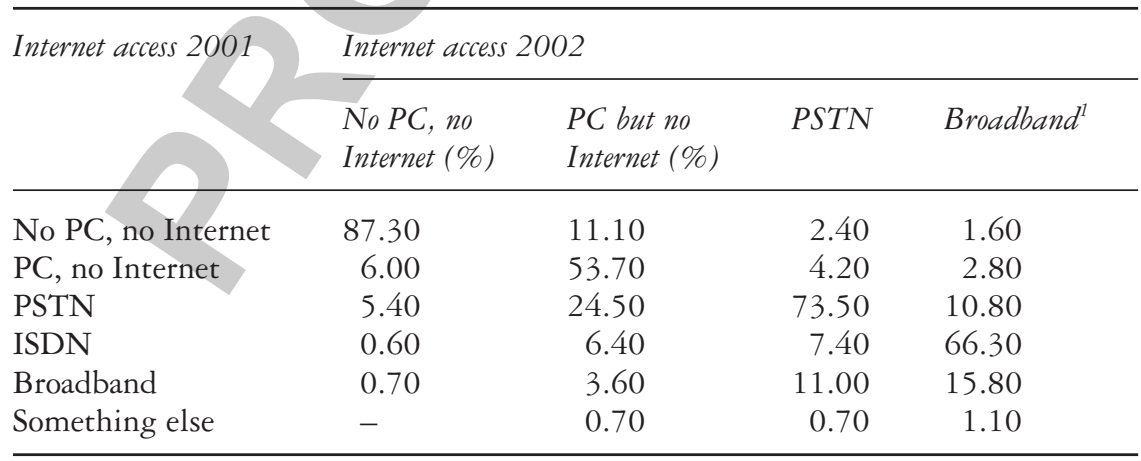

Note

1 Defined as 'at least cable modem or ADSL' - may also include other such as WIFI, ethernet etc. 


\section{The difference broadband makes}

There is considerable interest in the potential effects of broadband not only on Internet use or e-commerce but also on other activities such as TV viewing and social and leisure activities. However there is little or no evidence for these 'effects' from anything other than cross-sectional surveys which cannot, other than by error-prone respondent recall, account for the historical behaviour patterns of those who are broadband adopters. As a result the apparent changes in behaviour that are attributed to broadband adoption may in fact be due to differences between broadband and narrowband users in terms of socioeconomic status or Internet usage levels. This confusion is apparently endemic in the ICT market research community at this time (e.g. Nielsen/NetRatings, 2003; Kerner, 2004) and also, more surprisingly, in some quasi-academic literature (see, for example, Horrigan and Rainie, 2002). As an example, Nielsen/NetRating's May 2003 press release on broadband implied that the difference in online time between narrow and broadband users measured in a cross-sectional survey was 'caused' by the switch to broadband.

\section{Difference vs change}

To continue with this example, we might hypothesise that moving to broadband would increase the minutes spent online due to the probable switch to flat-rate pricing. On the other hand, we might hypothesise that people would spend less time as the speed should enable them to complete their tasks more quickly. Or indeed there may be no difference in time spent online since there may be only a fixed portion of time available to individuals in any given day for Internet use. Let us first consider the case of a cross-sectional survey.

Figure 4.1 shows the typical results of a cross-sectional survey and, by comparing the means, we can see that, in the UK, Norway and Israel, broadband users do indeed spend more time online than narrowband users. However, we cannot conclude from this chart alone that broadband is causing this difference; it is just as likely to be caused by the socio-demographic profiles of early broadband users.

Figure 4.2 addresses this problem by comparing the mean minutes spent online by narrowband users who did not move to broadband (wave one or two: PSTN 2001 and 2002) with those who did (wave one or two: PSTN $\rightarrow$ BB (before/after)). Now we can see that those who moved to broadband were already heavier users of the Internet before they switched; indeed this may have been one reason for them to do so. We can also see that it is only in the UK that moving to broadband from narrowband is associated with heavier Internet use in terms of minutes per week online.

Of course, this is still a relatively simple picture. We do not know the influence of Internet experience, age, gender or education, all of which may 


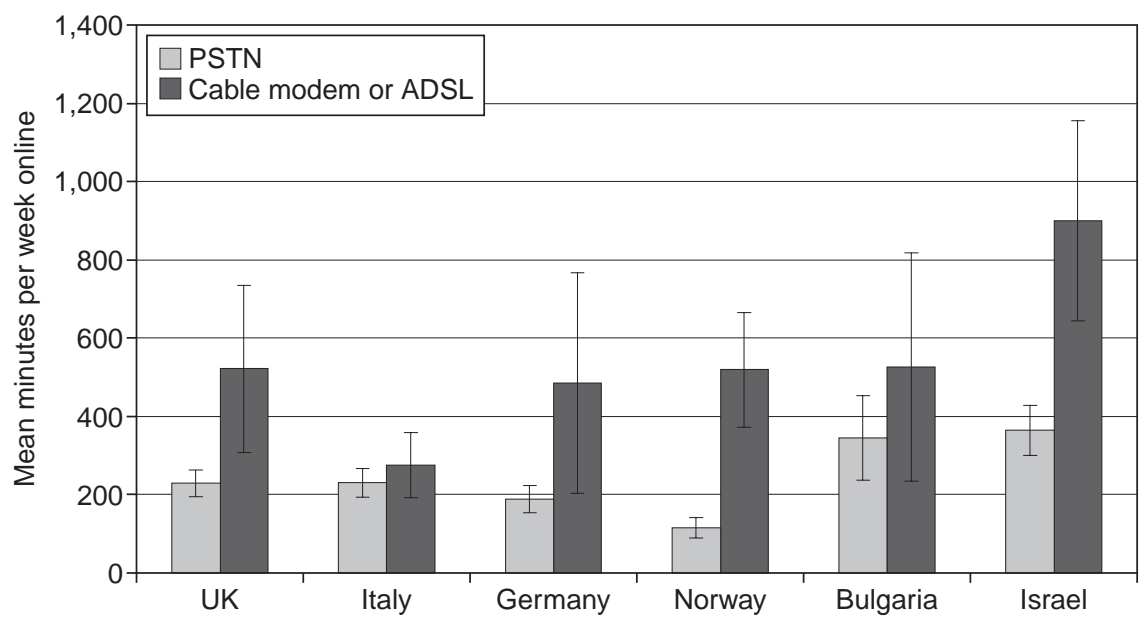

Figure 4.1 Mean minutes online per week for narrowband and broadband users (eLiving wave two, 2002, weighted for non-response).

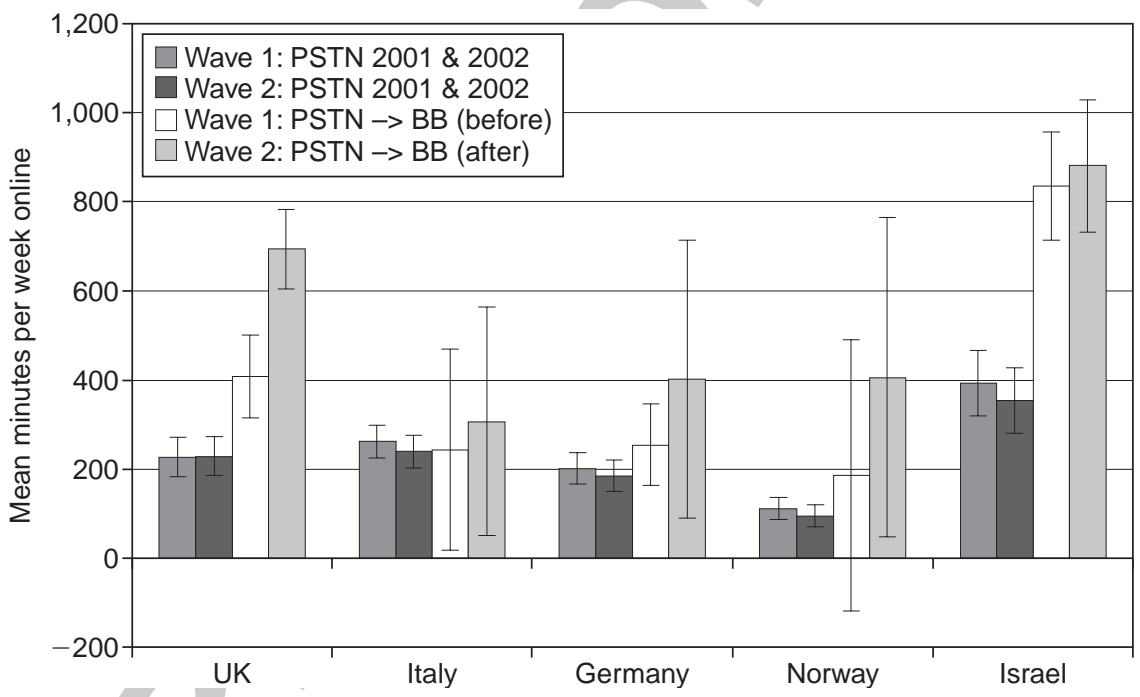

Figure 4.2 Mean minutes online per week for narrowband and broadband users as well as for broadband adopters (e-Living waves one and two, 2002, weighted for non-response).

be mediators of Internet use, as may changes in life stage or lifestyle such as getting (or losing) a job, becoming a parent or retiring. To overcome this problem, we need to use longitudinal regression models to predict current behaviour on the basis of historical behaviour and changes between waves one and two such as adopting broadband or losing a job. The remainder of 
the chapter does precisely this.

Table 4.3 shows the specification of these models. In the case of Internet and TV time, it is worth noting that, in order to ensure an approximation to the normal distribution of the dependent variable, we have used the square root of Internet time. In each case we have pooled all Internet users at waves one and two in all six countries in order to achieve a reasonable sample size, but have included dummy variables for the countries as controls to negate inter-country differences.

In the remainder of the chapter we present summaries of models we have developed to test the effects of adopting broadband on Internet time, TV watching time, social leisure activities and online spending which, taken together, represent a range of potential 'impacts' of broadband that are of interest in policy and commercial contexts. Two of these models (Internet time and e-commerce) produced evidence of effects and are discussed first, whilst the other two produced no evidence of effects.

\section{Internet time model}

In this case we want to know if moving from narrow to broadband is associated with an increase or decrease in time spent online, whilst controlling for previous Internet usage and other transitions.

For the Internet time model we used the time spent online at wave one to predict the time spent online at wave two; a range of socio-demographic variables, a number of transition variables, such as retiring or losing a job, and dummy variables for each country. We also included a dummy variable for switching to broadband, the respondent's wave-one Internet experience, a set of Internet behaviour change variables and a measure of change in TV watching.

Figure 4.3 shows the results of running this model. As we can see, the strongest predictor of current Internet time by a considerable margin was the amount of time spent online last year. This is hardly surprising people's habits do not change that quickly. Switching to broadband was the next strongest predictor followed by changes in two ICT behaviours - the frequency of emailing family and friends and the number of different online activities. These last two suggest that there is at least a mutually reinforcing relationship between email and other activities and time spent online as we might expect. Thus the more email people send and the more online activities they do, the more time they spend online. In the context of the information society, it is interesting to note that the effect for email (communication) was marginally stronger than the number of other online activities.

We can also see that retirement and losing a job made no difference, and nor did gaining a job. 


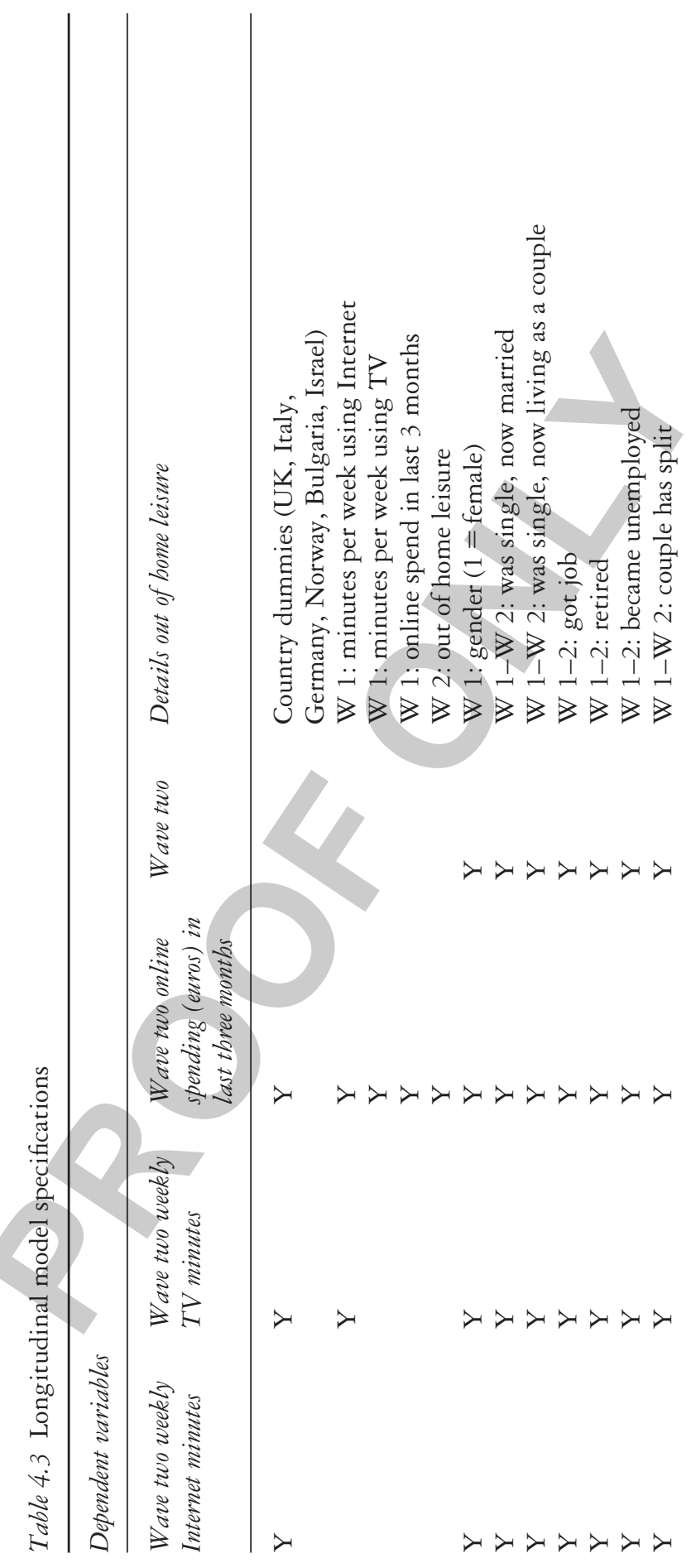




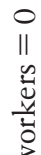

苟苞苞

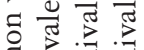

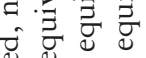

㟧

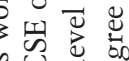

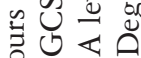

일 1

$\exists \vec{\nabla} \bar{\nabla}$

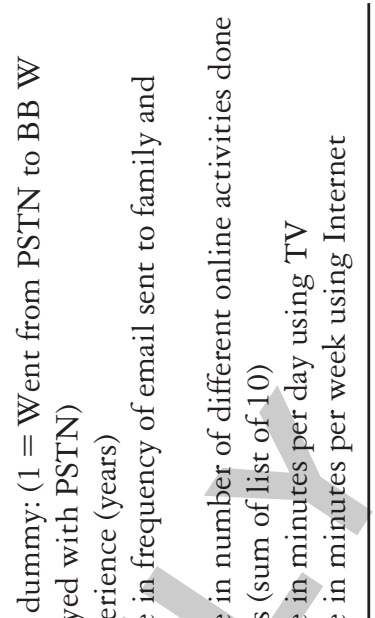

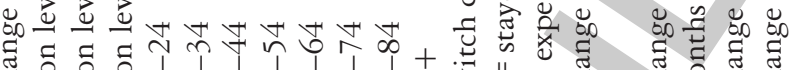

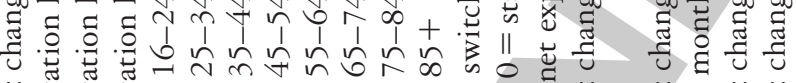

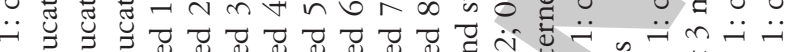

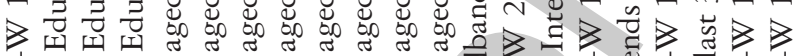

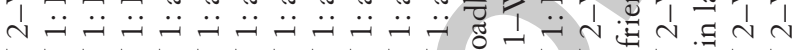

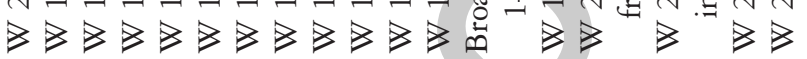

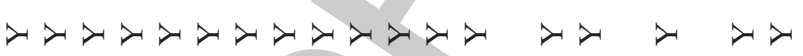

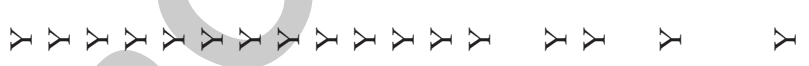

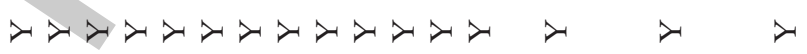




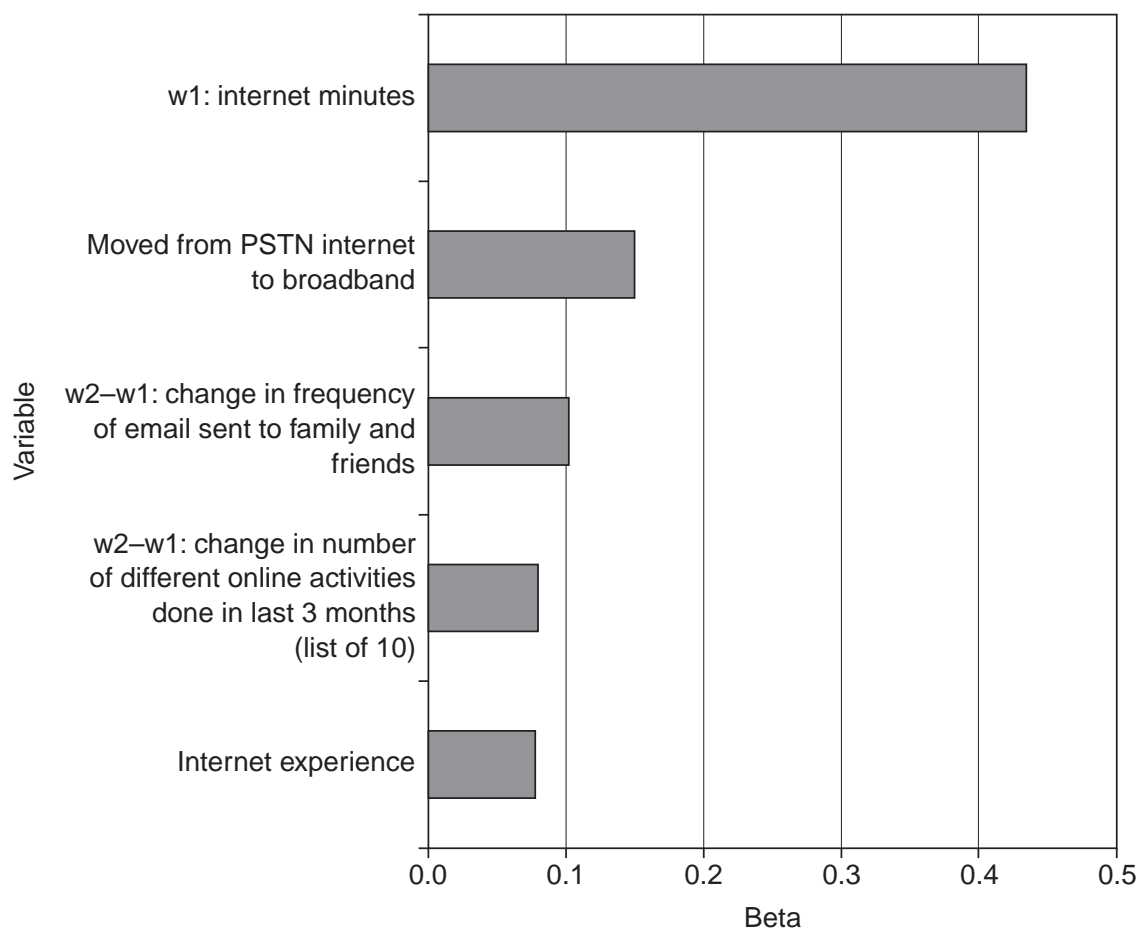

Figure 4.3 Internet time model results (substantive variables with $p<0.05$ shown, values $=$ beta (standardised coefficients), adjusted $R^{2}=0.352$, controls not shown).

\section{E-commerce model}

In this case we wanted to know if moving from narrow to broadband was associated with an increase or decrease in overall online spending. This model was again broadly similar to the previous two but includes the wave one and two spend variables and leaves out the ICT behaviour variables relating to email as we had no a priori reason to suppose that this will be linked to online spending. However we included Internet experience at wave one as it is known to correlate with online spending, as well as the level of Internet use at wave one (minutes online) and the change in time spent online between waves one and two.

The results of this model were rather similar to those for online time, except that now no effect was found for those who moved from narrow to broadband. Instead, the amount of online spend in the previous year together with time online and Internet experience were excellent predictors of current online spend. Undertaking more activities online and spending more time online was linked to spending more. 


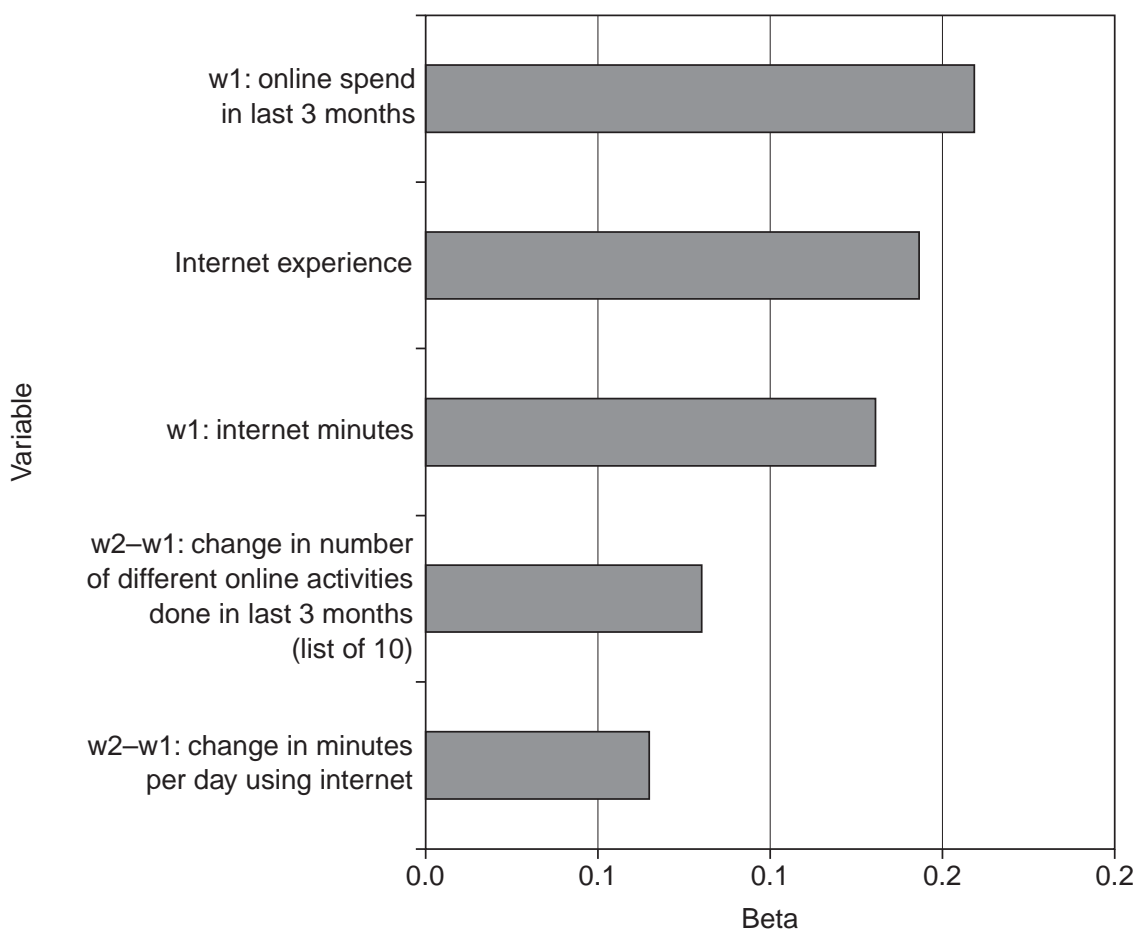

Figure 4.4 E-commerce model results (substantive variables with $p<0.05$ shown, values $=$ beta (standardised coefficients), adjusted $\left.R^{2}=0.200\right)$.

\section{TV time model}

In this model we wanted to know if moving from narrow to broadband was associated with an increase or decrease in time spent watching TV whilst controlling for previous TV usage.

The specification for this model was almost identical to the previous one, with the only difference being the use of TV watching time in wave two as estimated by the respondents at each wave as the dependent variable. We also kept the longitudinal ICT usage variables to see if changes in online activity had any effect on TV time.

Although it explained 33 per cent of the variance in the wave-two TV watching time (not shown), the only two variables that proved statistically significant were the amount of time spent watching TV at wave one, getting a job (negative) and the years of Internet experience (negative). No changes in Internet access mode or online behaviour had any significant effect on time spent watching TV. 


\section{Social leisure model}

In this model we wanted to know if moving from narrow to broadband was associated with an increase or decrease in out-of-home social activity. ${ }^{2}$ This model was similar to the previous three but, instead of the online spend variable, we used an index of social leisure constructed from the following question items describing the frequency of:

1 Playing sport, keep fit or go walking.

2 Going to the cinema, a concert, theatre or watch live sport.

3 Have a meal in a restaurant or cafe, or go for a drink to a bar.

4 Attending activity groups such as evening classes.

5 Meeting with friends.

These items were measured on a scale of $0-7$ with 0 meaning 'never' and 7 meaning 'most days'. The index used was simply the sum of these scores for each item so the more frequently an individual took part in these activities, the higher their score.

Although the model explained 44 per cent of the variance (again, not shown), the only variables that showed any statistically significant effects on the wave-two leisure score were the active leisure score for wave one and age (all age groups had significantly lower scores than the sixteen-to-eighteenyear-olds). Getting broadband Internet was not significant and nor was increasing time spent or activities undertaken online.

We repeated this analysis for each component part of the social leisure index and the patterns were identical in that switching from narrowband to broadband Internet made no difference to these scores.

\section{Conclusions}

The penetration of broadband Internet was still at an early stage in 2001 and 2002. Israel ranked with the UK, Germany and Norway in terms of households with PCs, but the UK had proportionately more narrowband (analogue modem) Internet households than any other country. ISDN dominated in Norway and, to some extent, in Germany. Some households had multiple modes of access, the most frequent in the UK being analogue modem and cable modem/ADSL and ISDN with analogue modem/cable in Germany and Norway. This reinforces a finding from earlier research, which suggested that new cable modem, and ADSL users were retaining their analogue modem access in case of broadband service failure (Anderson et al., 2003).

The four models that we have presented in this chapter have used unique longitudinal data to examine the effect of moving to broadband on four 'representative' activities of interest primarily to the ICT industry but also to policy-makers - Internet time, TV time, amount of money spent online 
and out-of-home social leisure activities. As we noted in the introduction to this chapter, a range of authors from market research consultancies to academics have commented on the impact of broadband on these aspects of life. It turns out that such 'impacts' are hard to substantiate when we have 'before' and 'after' data on the same individuals and can control for a range of other simultaneous life changes.

The greatest effect on time spent online is not moving to broadband, although this was significant, but the previous behaviour of an individual. We also noted the strong positive effect on time online of the frequency of emailing friends and relatives, thus confirming Kraut et al.'s similar finding for the USA (2000) and highlighting that it is not only Asian Internet users who are driven to a great extent by social communication. This should remind us that those looking for 'killer applications' may need to investigate 'social' rather than 'consumption' software more fully.

Given previous findings that have used longitudinal data to show that increased Internet time had a negative effect on television use (Gershuny, 2003), the results we see here suggest that, whilst this may be so, the result does not hold for switching from narrowband to broadband Internet at home. Indeed our results demonstrate the resilience of time spent watching TV to a range of life transitions.

We have no evidence that switching to broadband will have any effect on the amount of money individuals spend online. As with time online, we can instead see a steady progression of online spend driven largely by experience, not only in terms of years spent online, but in terms of breadth of Internet use. We can also see an overriding effect for successful previous e-commerce - since the driving factor for spend this year is the amount spent last year.

We also have no evidence that switching to broadband will have any effect on social leisure activities, even though more time may be spent online in contrast to the concerns of those such as Kraut et al. (1998) and Nie and Hillygus (2002).

Overall, the process of experienced or heavy Internet users moving to broadband largely explains the effects we see. Broadband users were, at this time at least, an unrepresentative group of Internet users. In the future, and possibly quite soon in some countries, less-experienced Internet users, as well as new users, will move to broadband. In this case we may see more of a broadband effect, although the constraints of everyday life suggest that it is only a small group of people in any cohort who exhibit significant behavioural change. There is simply not that much slack in most people's lives for major shifts in behaviour in the short term.

Finally we must also express some concerns about the potential distribution of any social benefits of broadband. We have seen that in the case of the Internet time and online spend models, it is those who have the most experience and greatest breadth of use who are doing and spending more. If this pattern continues, then broadband access will not change the structural problems already found in narrowband - those who have the knowledge and 
experience gain the most benefit, whilst those who lack the skills, knowledge and perhaps self-confidence are left further behind (Selwyn, 2005). This is not an issue that will be solved by technology, or by policies that focus on penetration and access, as opposed to utility, value and social outcomes.

\section{Acknowledgements}

This research was partially funded by the European Commission funded Framework 5 project e-Living (IST-2000-25409).

\section{Notes}

1 europa.eu.int/information_society/eeurope/2005/index_en.htm.

2 Unfortunately within this dataset we have no measures of intra-household social activity with which to test the hypothesis that heavier Internet usage may lead to less intra-household communication.

\section{Bibliography}

Anderson, B., Gale, C., Jones, M.L.R. and McWilliam, A. (2003) Domesticating broadband - what really matters to consumers. In Turnbull, J. and Garrett, S. (eds) Broadband Applications and the Digital Home, London, IEE.

Bangemann, M. (ed.) (1994) Europe and the Global Information Society: Recommendations to the European Council, Brussels, HLEG INFO-SOC.

CEC (2002) eEurope 2005: an Information Society For All - an Action Plan, Brussels, Belgium, Commission of the European Communities.

DTI (1994) Creating the Superbighways of the Future: Developing Broadband Communications in the UK, London, HMSO.

Dutton, W., Di Gennaro, C. and Hargrave, A.M. (2005) The Internet in Britain. The Oxford Internet Survey (OxIS) May 2005, Oxford, Oxford Internet Institute.

Firth, L. and Mellor, D. (2005) Broadband: benefits and problems. Telecommunications Policy, 29, 223-236.

Gallup Europe (2002) Flash Eurobarometer 135: Internet and the Public at Large Results and Comments. Online, available at: ec.europe.eu/public_opinion/flash/ f113s_en.pdf.

Gershuny, J. (2003) Web use and net nerds: a neo-functionalist analysis of the impact of information technology in the home. Social Forces, 82, 141-168.

Horrigan, J.B. and Rainie, L. (2002) The Broadband Difference: How Online American's Behavior Changes with High-speed Internet Connections at Home, Washington, DC, Pew Internet and American Life Project.

Ida, T. and Kuroda, T. (2004) Discrete choice analysis of demand for broadband in Japan. Interfaces for Advanced Economic Analysis Discussion Papers, Kyoto, Kyoto University.

ITU (2003) Birth of broadband. International Telecommunication Union Internet Report, Geneva, ITU.

Kerner, S. (2004) More Broadband Usage Means More Online Spending, ClickZ Network. 
Kraut, R., Lundmark, V., Patterson, M., Kiesler, S., Mukopadhyay, T. and Scherlis, W. (1998) Internet paradox: a social technology that reduces social involvement and psychological well-being? American Psychologist, 53, 1017-1031.

Kraut, R., Mukhopadhyay, T., Szczypula, J., Kiesler, S. and Scherlis, B. (2000) Information and communication: alternative uses of the Internet in households. Information Systems Research, 10, 287-303.

Kridel, D., Rappoport, P. and Taylor, L. (2002) The demand for high-speed access to the Internet. Topics in Regulatory Economics and Policy, 39, 11-22.

Lee, H., O'Keefe, R.M. and Yun, K. (2003) The growth of broadband and electronic commerce in South Korea: contributing factors. The Information Society, 19, 81-93.

Madden, G. and Simpson, M. (1997) Residential broadband subscription demand: an econometric analysis of Australian choice experiment data. Applied Economics, 29, 1073-1078.

Nie, N.H. and Hillygus, D.S. (2002) The impact of internet use on sociability: time-diary findings. IT E Society, 1, 1-20.

Nielsen/NetRatings (2003) Broadband Revolutionizing Europe's Internet Behaviour, London, Nielsen/NetRatings.

Paynter, J. and Chung, W. (2003) Factors influencing broadband uptake in New Zealand. Innovation: Management, Policy E Practice, 5, 170-188.

Robertson, A., Soopramanien, D. and Fildes, S. (2004) Understanding residential Internet service adoption patterns in the UK. Telektronikk, 4, 84-94.

Savage, S.J. and Waldman, D. (2005) Broadband Internet access, awareness, and use: analysis of United States household data. Telecommunications Policy, 29, 615-633.

Selwyn, N. (2005) Whose internet is it anyway? Exploring adults' (non)use of the internet in everyday life. European Journal of Communication, 20, 5-26. 